\title{
molecules
}

ISSN 1420-3049

http://www.mdpi.org

\section{Recent Developments in the Area of Asymmetric Transfer Hydrogenation}

\author{
Martin Wills ${ }^{\mathrm{a}, *}$, Matthew Palmer ${ }^{\mathrm{a}}$, Athene Smith ${ }^{\mathrm{a}}$, Jennifer Kenny ${ }^{\mathrm{a}}$ and Tim Walsgrove ${ }^{\mathrm{b}}$ \\ ${ }^{a}$ Department of Chemistry, University of Warwick, Coventry, CV4 7AL, UK \\ Tel.: (024) 7652 3260, Fax: (024) 7652 4112, E-mail: M.Wills@warwick.ac.uk \\ http://www.warwick.ac.uk/fac/sci/Chemistry/astaff/wills/ \\ ${ }^{\mathrm{b}}$ SmithKline Beecham Pharmaceuticals, Old Powder Mills, Nr Leigh, Tonbridge, Kent, TN11 9AN, \\ UK
}

*Author to whom correspondence should be addressed.

Received: 14 September 1999 / Accepted: 15 November 1999 / Published: 21 January 2000

\begin{abstract}
The use of an enantiomerically pure amino alcohol, coupled to a transfer hydrogenation process, in the asymmetric catalysis of the reduction of ketones to alcohols, is described. The process works well for unfunctionalised ketones, affording e.e.s of up to $98 \%$, and excellent conversions. We have recently extended, for the first time in this application, the scope of the methodology to the reductions of $\alpha$-heteroatom substituted substrates, through the use of the appropriate protecting groups on each atom.
\end{abstract}

Keywords: asymmetric, transfer, hydrogenation, catalysis, ruthenium.

\section{Introduction}

The asymmetric reduction of ketones to enantiomerically enriched alcohols remains a pivotal transformation in organic synthesis [1,2]. Of the methods available to achieve this reaction in a catalytic sense the most established are those based on either hydrogenation [3-7] or the use of oxazaborolidines for the catalysis of ketone reduction by borane $[8,9]$.

Catalytic hydrogenation using a homochiral phosphine in conjunction with an appropriate metal, usually rhodium or ruthenium, is a versatile method which requires only very low levels of catalyst. In

(C) 2000 by MDPI (http://www.mdpi.org). Reproduction is permitted for noncommercial purposes. 
general, however, the method is most suitable for ketones which bear a proximal co-ordinating group [3-7]. There are however a number of recent notable examples of reductions of simple ketones through the use of additives [10-13] and a remarkable system for the asymmetric hydrogenation of simple ketones using a combination of a $\mathrm{Rh}(\mathrm{I})$ complex of a chiral phosphine with lutidine and $\mathrm{KBr}$ as additives has been reported very recently [14].

The oxazaborolidine-catalysed borane reduction process is complementary to hydrogenation and is ideally suited to the reduction of unfunctionalised ketones and enones [8,9]. The drawback of this method is the requirement for a relatively large quantity (usually at least $10 \mathrm{~mol} \%$ ) of catalyst and the non-compatibility of certain functional groups with borane.

In this paper the combination of a homochiral amino alcohol with ruthenium(II) is demonstrated to form an effective new system for the asymmetric catalysis of the transfer of hydrogen from isopropanol to acetophenone.

\section{Transfer Hydrogenation of Ketones}

Asymmetric transfer hydrogenation with $\mathrm{Ru}(\mathrm{II})$ complexes, in which we have recently commenced a programme of research, has recently emerged as an effective approach to asymmetric carbonyl reduction [15].

A particular advantage of transfer hydrogenation methodology is the requirement for only very low quantities of catalysts; typically less than $1 \mathrm{~mol} \%$. Furthermore the ligands employed are often are indefinitely stable to the reaction conditions and may be recovered after use.

We have recently discovered that $(1 \mathrm{R}, 2 \mathrm{~S})-(+)-\mathbf{1}$ is an excellent ligand for asymmetric transfer hydrogenation of ketones (Scheme 1) [16]. The use of 1 mol\% of 1 in conjunction with $0.25 \mathrm{~mol} \%$ of the ruthenium complex $\left[\mathrm{RuCl}_{2} \text { (p-cymene) }\right]_{2}$ and $2.5 \mathrm{~mol} \%$ of $\mathrm{KOH}$ in propan-2-ol ([ketone $\left.]=0.1 \mathrm{M}\right)$ at room temperature resulted in reduction of acetophenone to S-(-)-1-phenethanol in $70 \%$ isolated yield and $91 \%$ e.e. after 90 minutes. Of a series of aromatic groups in the catalyst, p-cymene proved to be superior to benzene and 1,3,5-trimethylbenzene. The reaction does not require exclusion of water or air and may be worked up simply by filtration of the reaction mixture through a plug of silica followed by removal of solvent.

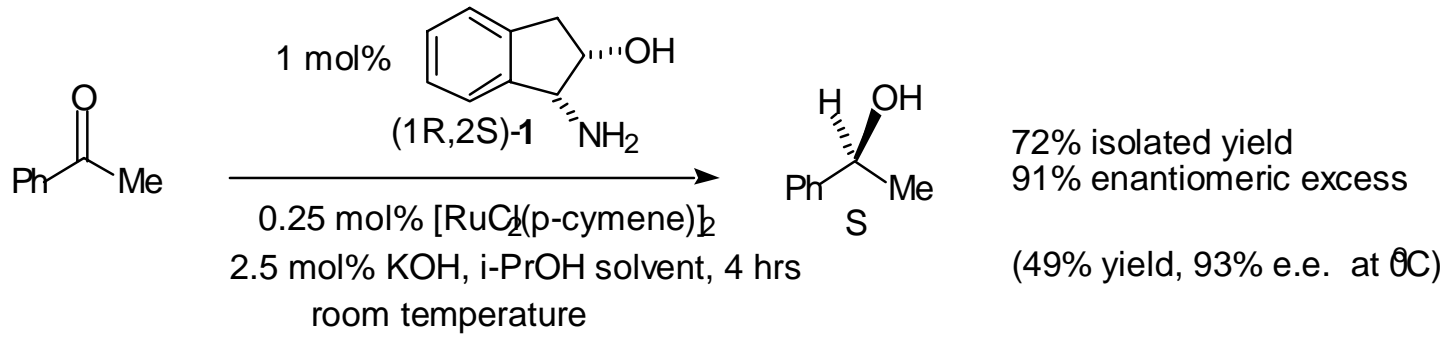

Scheme 1. Asymmetric transfer hydrogenation of acetophenone using (1R,2S)-1.

The presence of a primary amine function on the ligand appears to be crucial; use of the methylated amine gave a product of only $20 \%$ e.e. In order to determine the importance of the rigid structure of the 
ligand we repeated the reaction under identical conditions using R-phenylglycinol 2. In this reaction S(-)-phenethanol was obtained in $95 \%$ yield but only $23 \%$ enantiomeric excess (Scheme 2). Although we have not yet investigated a systematic series of ligand modifications, it appears that a primary amine function in the ligand is essential. We have also established that the relationship between the enantiomeric purity of the ligand and the e.e. of the product is linear, suggesting that the active catalyst contains a 1:1 ligand:Ru ratio [17].

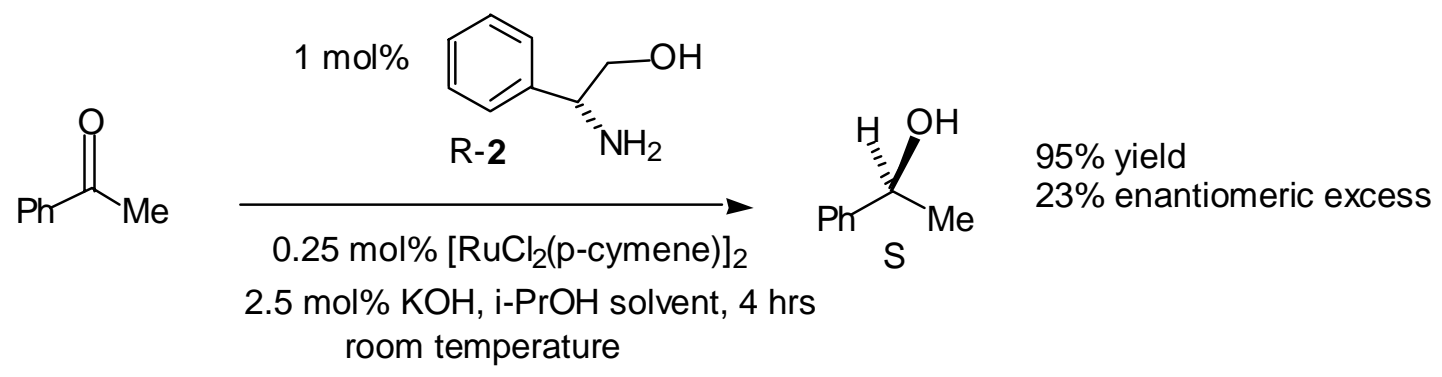

Scheme 2. Asymmetric transfer hydrogenation of acetophenone using (R)-2.

Reduction of a series of aromatic ketones under identical conditions using ligand $\mathbf{1}$ resulted in formation of the corresponding alcohols in good to excellent yields and enantiomeric excesses (Figure 1). The reduction of 1-tetralone gave the most remarkable result; up to $98 \%$ enantiomeric excess under the room temperature reduction conditions. Extended reaction times resulted in loss of selectivity due to he reversibility of the reaction. Isolated yields of only 39 to $63 \%$ were obtained however when account was taken of the quantity of recovered starting material the mass balance is generally excellent. In all instances where e.e.s are observed to reduce over extended times it is likely that this is a result of the slow reversibility of the reaction.

Although aromatic/alkyl ketones were generally good substrates, alkyl/alkyl ketones gave products of lower enantiomeric excess. An exception to this trend was observed for 2-tetralone, which gave a product of $81 \%$ e.e., which represents a result competitive with any of the best alternative methods.

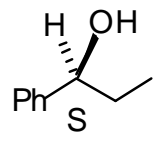

$84 \%$ yield $86 \%$ e.e.

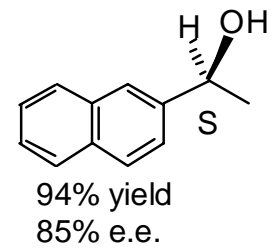

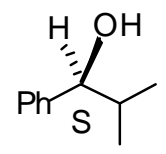

$90 \%$ yield $43 \%$ e.e.

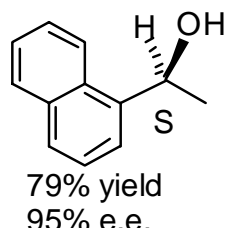<smiles>O[C@H]1CCc2ccccc2C1</smiles>

$85 \%$ yield $81 \%$ e.e.

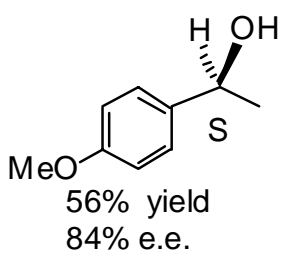

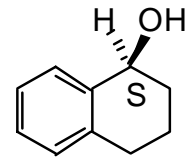

48 hours: $60 \%$ yield $67 \%$ e.e.

4 hours: $40 \%$ yield, $98 \%$ e.e.

Figure 1. Asymmetric transfer hydrogenation of ketones using $1 \mathrm{~mol} \%(1 \mathrm{R}, 2 \mathrm{~S})-\mathbf{1}$, $0.25 \%\left[\mathrm{RuCl}_{2} \text { (p-cymene) }\right]_{2}, 2.5 \mathrm{~mol} \% \mathrm{KOH}$, i-PrOH solvent, $1,5 \mathrm{hrs}$, room temperature. 
Our speculation on the mechanism of the reaction follows on from the suggestion by Noyori that hydrogen bonding may play a key role in the catalytic process [18]. This speculation has been supported by a series of enlightening X-ray crystallographic studies [19]. We have obtained results which suggest a 1:1 relationship between the ligand and the metal and have observed that the nature of the aryl group has an effect on the enantiomeric excess [16]. This leads us to suggest that the 'procatalyst' is probably an 18 electron compound such as $\mathbf{3}$, which forms upon treatment of the ligand $\mathbf{1}$ and the ruthenium complex precursor with base. Further elimination of $\mathrm{HCl}$ allows the active catalyst to form and enter the catalytic cycle of hydrogen transfer (Scheme 3) in a process analogous to that proposed by Noyori.

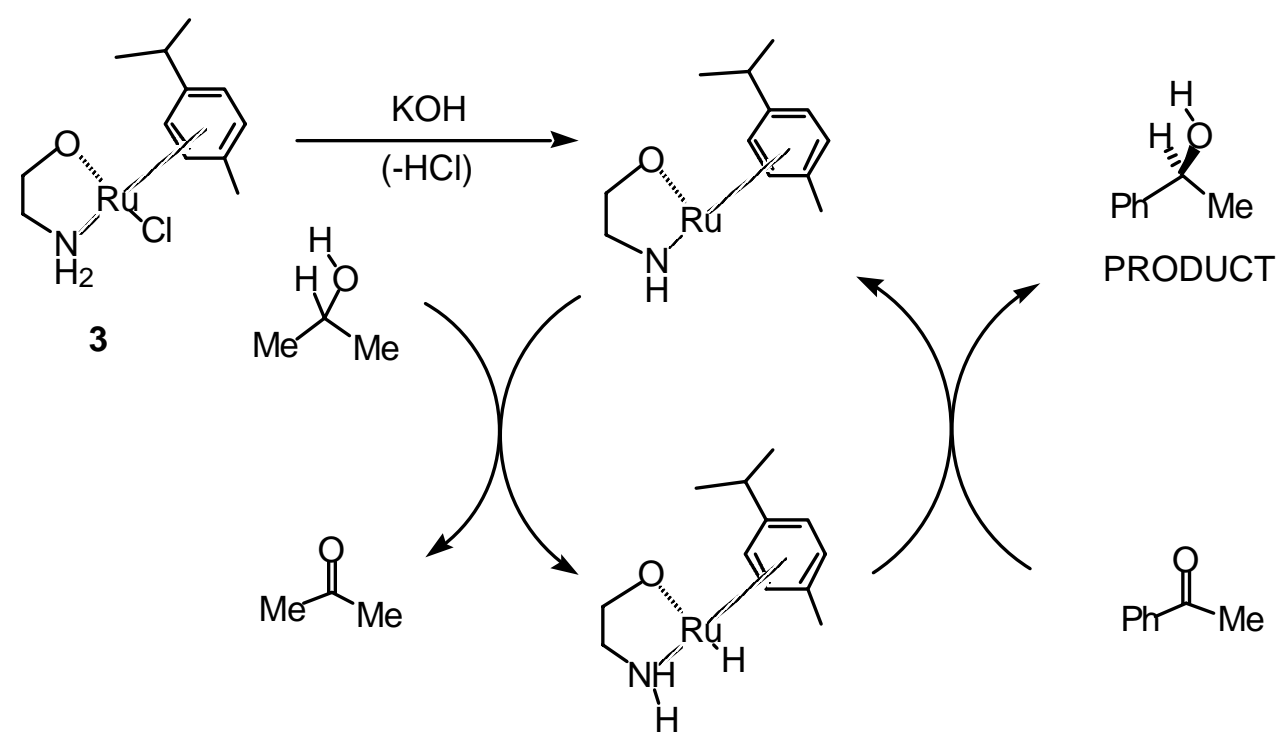

Scheme 3. Proposed catalytic cyclic for transfer hydrogenation using (1R,2S)-1 as catalyst.

The origin of the asymmetric induction is less clear, however the highly rigid nature of the amino indanol ligand ensures that any complex will be well defined. In this the hydrogenated ligand will have a choice of two geometries for complexation (Figure 2), one of which is likely to be rather more congested than the other and thus disfavoured.

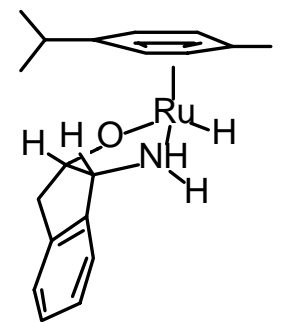

Favoured

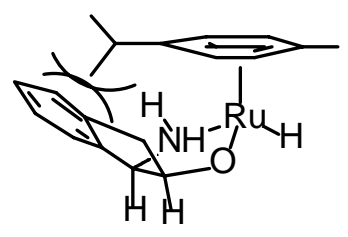

Disfavoured

Figure 2. Possible diastereomeric complexes of 1 and rutheniu(arene)C. 
Having thus generated a rigid and well defined chiral environment in the complex, the hydrogen transfer, which may involve a hydrogen bond from the amine nitrogen atom to the carbonyl oxygen, will take place in a stereochemically predictable manner (Figure 3). We have no direct evidence, however, for the structure shown in Figure 3, which is our present speculation and the subject of ongoing investigations [17].

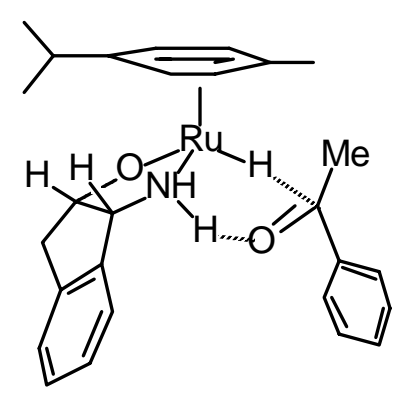

Figure 3. Proposed transition state for asymmetric reduction.

With a view to extending the transfer hydrogenation methodology to a variety of substrates we have studied the reductions of a series of $\alpha$-heteroatom substituted ketones (the results are summarised in Figure 4). The reaction of $\alpha$-chloro acetophenone 4 failed to give any product, a result which we initially explained by assuming in-situ cyclisation to the epoxide and thus deactivation of catalyst by neutralisation of the base. However we were most surprised by the same lack of reactivity of both $\alpha$-methoxy and $\alpha$-amino substituted ketones 5 and $\mathbf{6}$. It was clearly the case either these ketones were poor substrates $o r$ that some form of product inhibition was terminating the catalytic process.

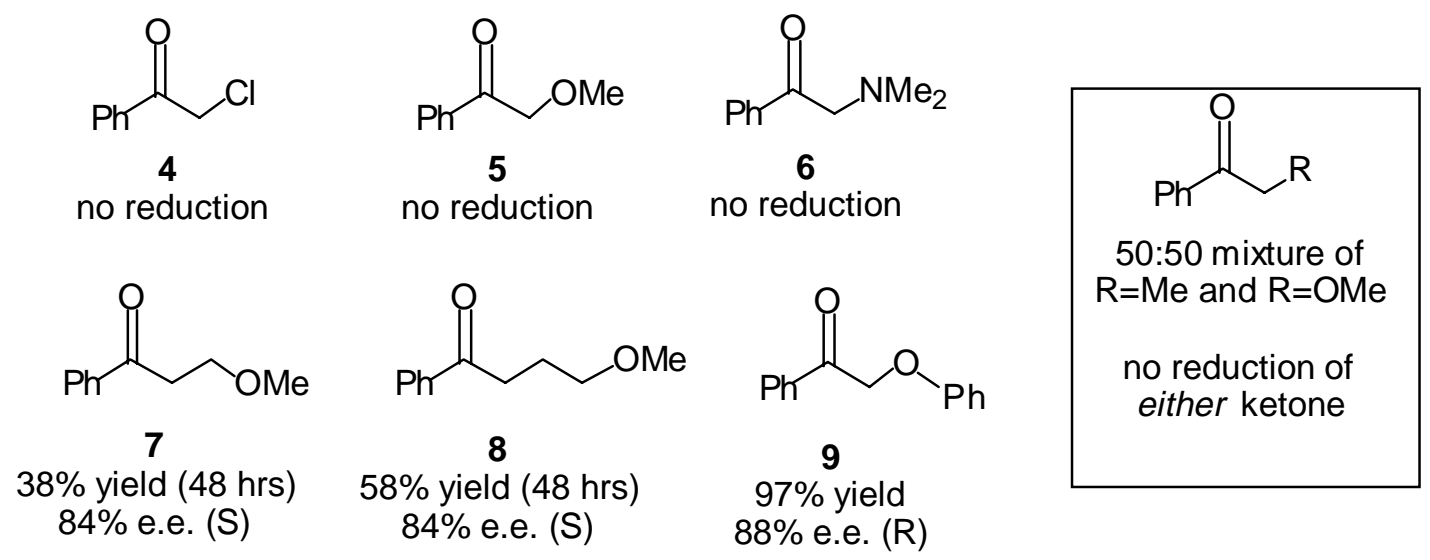

Figure 4. Results of asymmetric transfer hydrogenation substrates bearing $\alpha$-heteroatom functions (1 mol\% (1R,2S)-1, $0.25 \mathrm{~mol} \%\left[\mathrm{RuCl}_{2} \text { (p-cymene) }\right]_{2}, 2.5 \mathrm{~mol} \% \mathrm{KOH}$, i-PrOH solvent, 1,5 hrs, room temperature). 
In order to test this we examined the transfer hydrogenation of a 1:1 mixture of propiophenone (which is known to be a good substrate) and $\alpha$-methoxyacetophenone. In the event neither ketone was reduced, thus confirming that the catalyst is clearly inhibited by certain substrates or their reduction products. Our present speculation is that the formation of a chelating product results in inhibitory complexation and ultimately decomposition of the catalytic species (Figure 5) [20]. The proposed complex is a 20-electron complex and is likely to undergo rapid decomposition through loss of the aromatic ring.

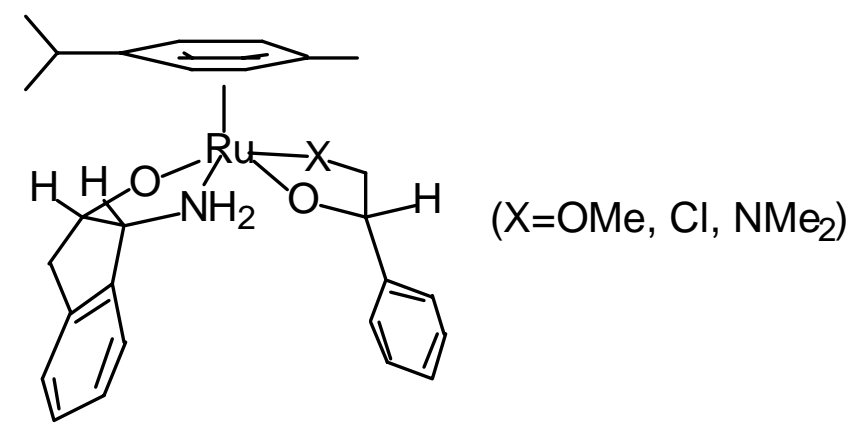

Figure 5. Proposed intermediate leading to catalyst inactivation by a chelating product.

Further investigations have added support to the product inhibition theory. Reduction of $\beta$-methoxy substituted ketone 7 proceeds rather more slowly than the acetophenone reaction whilst reduction of $\gamma$ methoxy substituted ketone $\mathbf{8}$ is once again a rapid process. These results suggest that, as one would predict, an increase in the distance between the potential chelating groups in the product causes the inhibitory effect to decrease sharply. Furthermore the reduction of $\alpha$-phenoxy substituted acetophenone 9 proceeds rapidly and with high selectivity; a valuable and noteworthy result [20]. In the latter case the lone pair of the oxygen atom adjacent to phenyl is delocalised with the aromatic group and is thus unavailable to contribute to a strongly chelating product.

Armed with a realistic hypothesis for the mechanism of inhibition we have been able to design functionalised systems which are compatible with transfer hydrogenation reactions under our conditions. Mindful of the need to deactivate the electron-donating ability of the alkoxy substituted substrates we have discovered that the acylation of the adjacent hydroxy group gives a substrate which is both rapidly and selectivity reduced to the acylated diol (Scheme 4). Although some product of acyl transfer is isolated, both products are of essentially identical e.e. and we have therefore assumed that the isomerisation process follows the reduction reaction. To our knowledge this is the first example of the reduction of an $\alpha$-alkoxy functionised substrate containing a removable protecting group under these conditions of transfer hydrogenation [20]. 


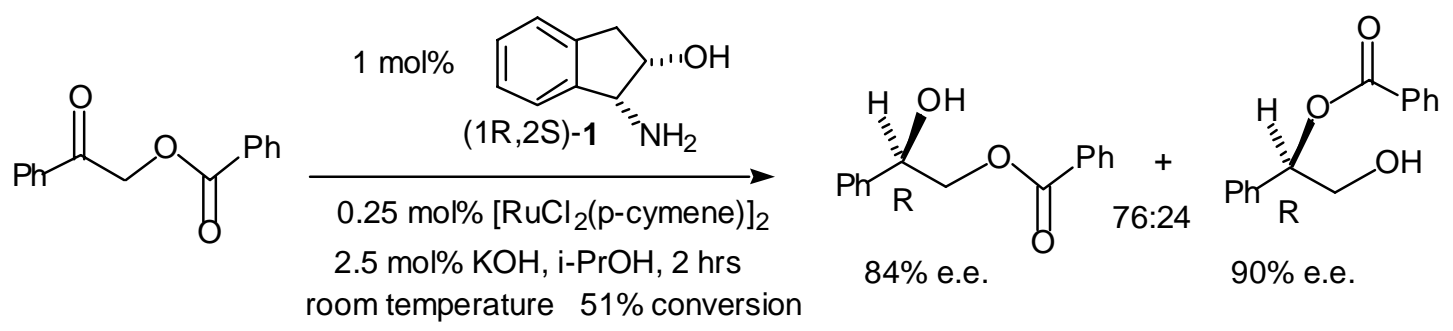

Scheme 4. Asymmetric transfer hydrogenation of $\alpha$-acyloxy substrates using (1R,2S)-1.

In a similar manner we have demonstrated that $\alpha$-amino substituted substrates bearing an electronwithdrawing group on the nitrogen atom are valuable reagents for our process (Scheme 5) [20]. In our example the use of an acylated primary amine function gave no reduction, however Noyori has reported one example of the reduction of a substrate containing such a functional group [15s].
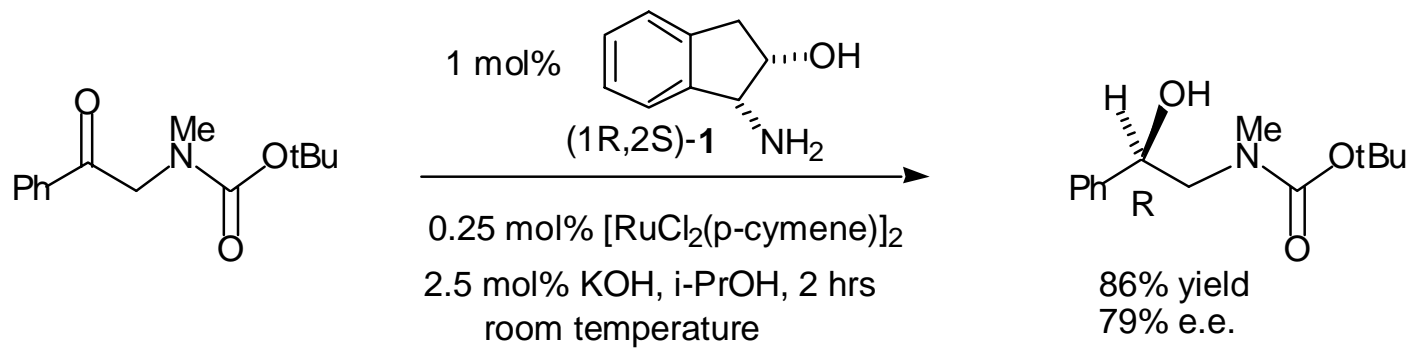

Scheme 5. Asymmetric transfer hydrogenation of $\alpha$-acylamino substrates using (1R,2S)-1.

It is also noteworthy that, since our own studies, the highly enantioselective asymmetric reduction of $\alpha$-chloroacetophenone using a combination of formic acid/triethylamine in conjunction with a ruthenium(II)/monotosylated diamine system has recently been reported [21].

In conclusion it has been demonstrated that transfer hydrogenation using stereochemically rigid amino alcohols is a versatile and practical method for the synthesis of enantiomerically enriched secondary alcohols. Recent developments have extended the scope of the reaction system to substrates containing heteroatoms adjacent to the ketone, thus greatly increasing the applicability of the system. Our current research portfolio in this area is focused at the extension of the methodology to related systems, the reduction of $\mathrm{C}=\mathrm{N}$ bonds [22], the solid phase support of our reagents [23], [151] and the reverse process, which allows kinetic resolution of alcohols through an enantioselective oxidation [24].

Acknowledgements: I wish to extend my thanks to the organisers of this online conference for the invitation to contribute a paper. I am indebted to the EPSRC and SmithKline Beecham (Tonbridge) for funding through CASE awards to Matthew Palmer and Jennifer Kenny. Oxford Asymmetry international have provided some very generous recent funding to extend the transfer hydrogenation work further. 


\section{References and Notes}

1. Noyori, R. Asymmetric Catalysis in Organic Synthesis; John Wiley and Sons Ltd: NY, 1994.

2. Ojima, I. Catalytic Asymmetric Synthesis; VCH Press: Berlin, 1993.

3. Noyori, R. Chemical multiplication of chirality - science and applications. Chem. Soc. Rev. 1989, 18, 187-208.

4. Noyori, R.; Takaya, H. BINAP - An efficient chiral element for asymmetric catalysis. Acc. Chem. Res. 1990, 23, 345-350.

5. Takaya, H.; Ohno, T.; Noyori, R. In Catalytic Asymmetric Synthesis; Ojima, I., Ed.; VCH: New York, 1993, Chapter 1.

6. Noyori, R. Organometallic ways for the multiplication of chirality. Tetrahedron 1994, 50, 42594292.

7. Wills, M. in Supplement A3: The chemistry of double-bonded functional groups; Patai, S., Ed.; John Wiley and Sons Ltd, 1997, pp 781-842.

8. Deloux, L.; Srebnik, M. Asymmetric boron-catalyzed reactions. Chem. Rev. 1993, 93, 763-784.

9. Wallbaum, S.; Martens, J. Asymmetric syntheses with chiral oxazaborolidines. Tetrahedron Asymmetry 1992, 3, 1475-1504.

10. Ohkuma, T.; Ooka, H.; Hashiguchi, S.; Ikariya, T.; Noyori, R. Practical enantioselective hydrogenation of aromatic ketones. J. Am. Chem. Soc. 1995, 117, 2675-2676.

11. Ohkuma, T.; Ooka, H.; Yamakawa, M.; Ikariya, T.; Noyori, R. Stereoselective hydrogenation of simple ketones catalyzed by Ruthenium(II) complexes. J. Org. Chem. 1996, 61, 4872-4873.

12. Ohkuma, T.; Ikehira, H.; Ikariya, T.; Noyori, R. Asymmetric hydrogenation of cyclic alpha,betaunsaturated ketones to chiral allylic alcohols. Synlett 1997, 467-469.

13. Ohkuma, T.; Ooka, H.; Ikariya, T.; Noyori, R. Preferential hydrogenation of aldehydes and ketones. J. Am. Chem. Soc. 1995, 117, 10417-10418.

14. Jiang, Q.; Jiang, Y.; Xiao, D.; Cao, P.; Zhang, X. Highly enantioselective hydrogenation of simple ketones catalyzed by a Rh-PennPhos complex. Angew. Chem., Int. Edn. Engl. 1998, 37, 11001103.

15. A summary of ligands (including our own) which have recently been reported for the asymmetric transfer hydrogenation of ketones are given below. For reasons of space the comparison is limited to the reduction of acetophenone. 
$\mathrm{X}_{\mathrm{E}}^{\mathrm{H}} \underbrace{\mathrm{H}}_{\mathrm{PPh}_{2}}$<smiles>C[C@H](CP)Pc1ccccc1</smiles>

$(\mathrm{R}, \mathrm{R})$-DIOP 1<smiles>CC1CCC(C(C)C)C(Pc2ccccc2)C1</smiles>

MDPP 3

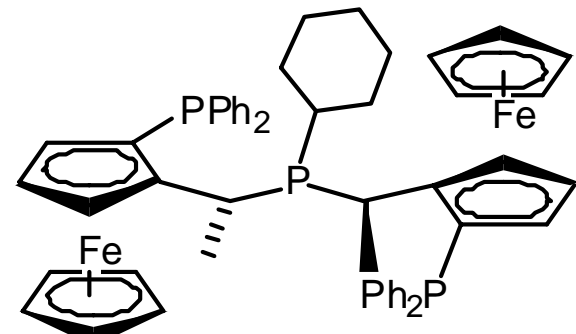

4 (pigiphos)

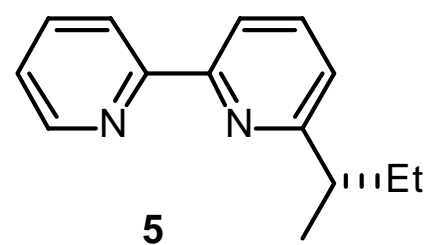

5<smiles>[B]C(C)C1COC(C2=N[C@@H](C(C)C)CO2)=N1</smiles>

8<smiles>CNC(=P)[C@@H](NC)c1ccccc1</smiles>

11

12 (poly(urea) of 11)<smiles></smiles>
$15^{15 p}$

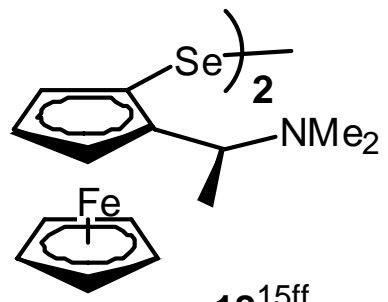

$18^{15 f f}$<smiles>CC(C)CC(C)c1cnc2c(ccc3cccnc32)c1</smiles>

6<smiles>c1ccc([C@H]2COC(CCNCCC3=N[C@H](c4ccccc4)CO3)=N2)cc1</smiles><smiles>O=C(Nc1ccccc1)N[C@@H](c1ccccc1)[C@H](NC(=O)Nc1ccccc1)c1ccccc1</smiles>

13

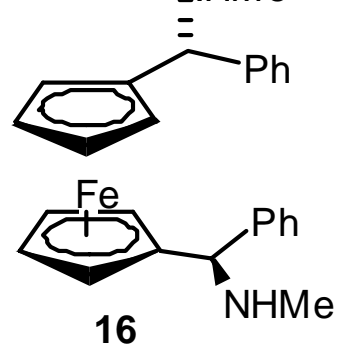

16

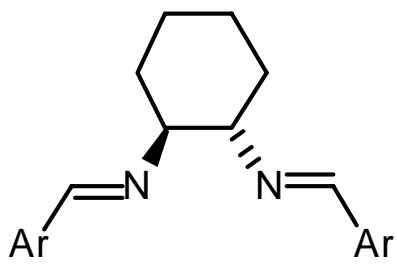

$19(\mathrm{Ar}=1$-naphthyl $)$<smiles>CC(/N=C/c1ccccn1)c1ccccc1</smiles><smiles>OC(CN(Cc1ccccc1)C[C@H](O)c1ccccc1)c1ccccc1</smiles>

10<smiles>NC(=S)N[C@@H](/C(NC(=S)Nc1ccccc1)=[PH]\c1ccccc1)c1ccccc1</smiles>

14

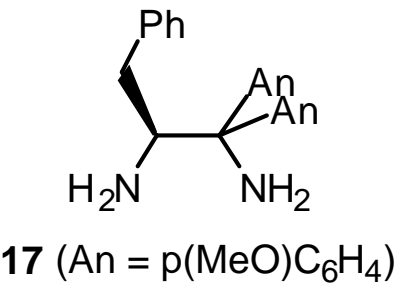



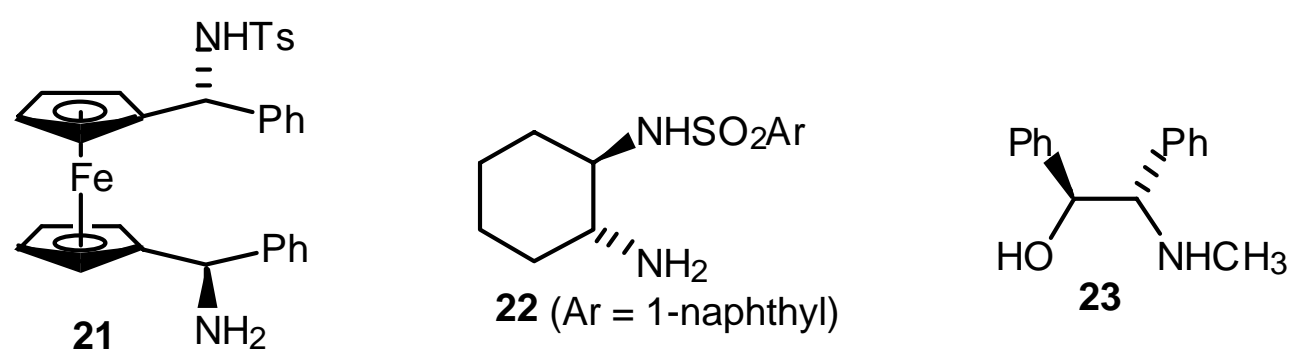

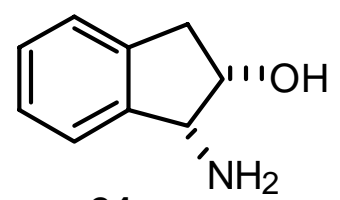

24

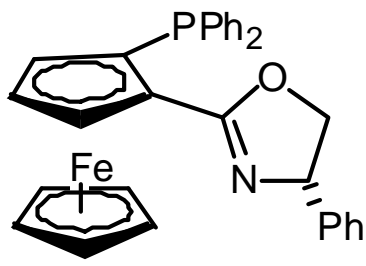

27

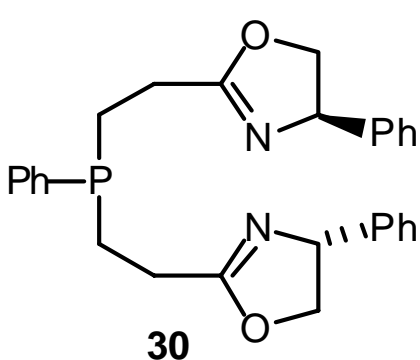

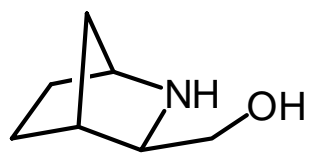

25<smiles>C[C@@H](Pc1ccccc1)c1cccc([C@H](C)c2ccccc2)n1</smiles>

28

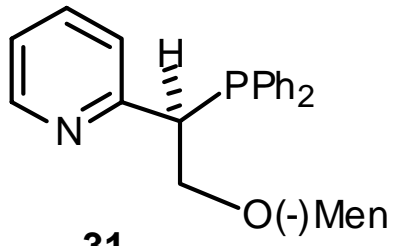

31
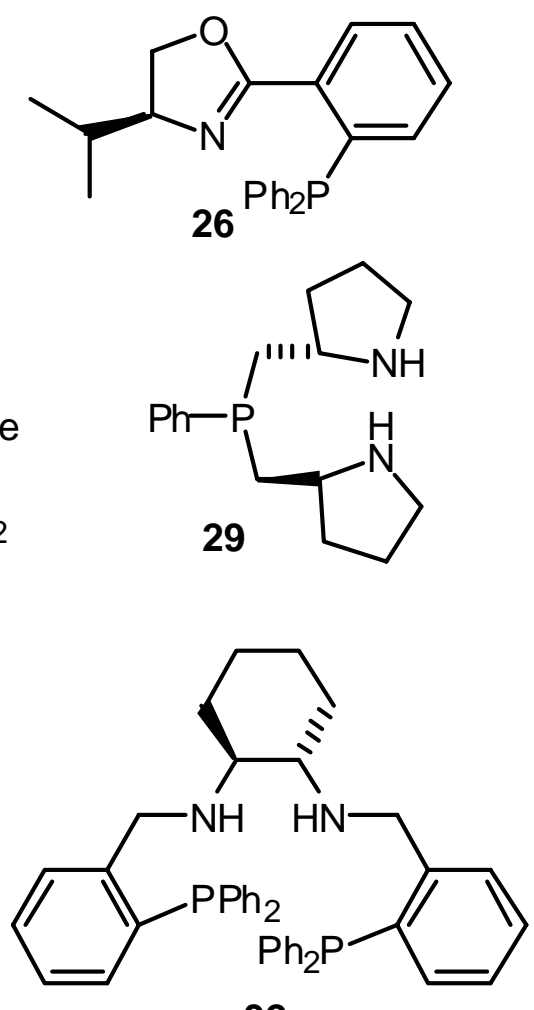

32 
Table. Asymmetric transfer hydrogenation of acetophenone (hydride source / solvent is isopropanol unless otherwise indicated).

$\begin{array}{cccccccc}\text { Entry } & \text { Ligand } & \text { Metal } & \text { Time, h } & \text { Temp, }{ }^{\circ} \text { C } & \text { Yleld, \% } & \text { e.e., \% } & \text { Ref } \\ 1 & \mathbf{1} & \operatorname{Ru}(\mathrm{II}) & 111 & 120 & 35 & 4(\mathrm{~S}) & \mathrm{a} \\ 2 & \mathbf{2} & \mathrm{Rh}(\mathrm{I}) & 3.5 & 82 & 60 & 9(\mathrm{R}) & \mathrm{b} \\ 3 & \mathbf{2} & \mathrm{Ir}(\mathrm{I}) & 23 & 82 & 71 & 58(\mathrm{~S}) & \mathrm{b} \\ 4 & \mathbf{2} & \mathrm{Ru}(\mathrm{II}) & 0.03 & 100 & 80 & 52(\mathrm{~S}) & \mathrm{b} \\ 5 & \mathbf{3} & \mathrm{Ir}(\mathrm{I}) & 3 & 82 & 87 & 42(\mathrm{~S}) & \mathrm{c} \\ 6 & \mathbf{4} & \mathrm{Ru}(\mathrm{II}) & 120 & 68 & 99 & 72(\mathrm{R}) & \mathrm{d} \\ 7 & \mathbf{5} & \mathrm{Rh}(\mathrm{I}) & - & 82 & - & 7(\mathrm{R}) & \mathrm{e} \\ 8 & \mathbf{6} & \mathrm{Rh}(\mathrm{I}) & 4 & 82 & 89 & 63(\mathrm{~S}) & \mathrm{f} \\ 9 & \mathbf{7} & \mathrm{Ir}(\mathrm{I}) & - & 82 & 89 & 37(\mathrm{~S}) & \mathrm{g} \\ 10 & \mathbf{8} & \mathrm{Ir}(\mathrm{I}) & 3 & 80 & 89 & 58(\mathrm{R}) & \mathrm{h} \\ 11 & \mathbf{9} & \mathrm{Ru}(\mathrm{II}) & 0.17 & 82 & 91 & 97(\mathrm{~S}) & \mathrm{i} \\ 12 & \mathbf{1 0} & \mathrm{Sm}(\mathrm{III}) & 2 & \mathrm{rt} & 74 & 96(\mathrm{R}) & \mathrm{j} \\ 13 & \mathbf{1 1} & \mathrm{Rh}(\mathrm{I}) & 168 & \mathrm{rt} & 100 & 67(\mathrm{R}) & \mathrm{k} \\ 14 & \mathbf{1 2} & \mathrm{Rh}(\mathrm{I}) & 24 & 70 & 100 & 60(\mathrm{~S}) & 1 \\ 15 & \mathbf{1 3} & \mathrm{Rh}(\mathrm{I}) & 163 & 60 & 97 & 43(\mathrm{R}) & \mathrm{m} \\ 16 & \mathbf{I 4} & \mathrm{Ru}(\mathrm{II}) & 9 & 82 & 98 & 87(\mathrm{~S}) & \mathrm{n} / \mathrm{o} \\ 17 & \mathbf{1 6} & \mathrm{Ru}(\mathrm{II}) & 120 & -30 & 98 & 30(\mathrm{R}) & \mathrm{p} \\ 18 & \mathbf{1 7} & \mathrm{Ir}(\mathrm{I}) & 12 & \mathrm{rt} & 74 & 78(\mathrm{R}) & \mathrm{q} \\ 19 & \mathbf{1 9} & \mathrm{Ru}(\mathrm{II}) & 2-8 & 82 & 89 & 28(\mathrm{~S}) & \mathrm{r} \\ 20 & \mathbf{2 0} & \mathrm{Ru}(\mathrm{II}) & 15 & \mathrm{rt} & 95 & 97(\mathrm{~S}) & \mathrm{s} \\ 21 & \mathbf{2 0} * & \mathrm{Ru}(\mathrm{II}) & 20 & \mathrm{rt} & 99 & 98(\mathrm{~S}) & \mathrm{t} \\ 22 & \mathbf{2 1} & \mathrm{Ru}(\mathrm{II}) & 24 & \mathrm{rt} & 97 & 56(\mathrm{R}) & \mathrm{u} \\ 23 & \mathbf{2 1} * & \mathrm{Ru}(\mathrm{II}) & 120 & \mathrm{rt} & 42 & 83(\mathrm{R}) & \mathrm{u} \\ 24 & \mathbf{2 2} * & \mathrm{Ru}(\mathrm{II}) & 24 & 30 & 99 & 96(\mathrm{R}) & \mathrm{u} \\ 25 & \mathbf{2 3} & \mathrm{Ru}(\mathrm{II}) & 1 & \mathrm{rt} & 94 & 92(\mathrm{~S}) & \mathrm{v} \\ 26 & \mathbf{2 4} & \mathrm{Ru}(\mathrm{II}) & 1.5 & \mathrm{rt} & 70 & 91(\mathrm{~S}) & \mathrm{w} \\ 27 & \mathbf{2 5} & \mathrm{Ru}(\mathrm{II}) & 5 & 83 & 95 & 95(\mathrm{~S}) & \mathrm{x} \\ 28 & \mathbf{2 6} & \mathrm{Ru}(\mathrm{II}) & 0.5 & 82 & 74 & 86(\mathrm{R}) & \mathrm{y} \\ 29 & \mathbf{2 7} & \mathrm{Ru}(\mathrm{II}) & 7 & 28 & 80 & 94(\mathrm{R}) & \mathrm{z} \\ 30 & \mathbf{2 8} & \mathrm{Ru}(\mathrm{II}) & 24 & \mathrm{rt} & 91 & 35(\mathrm{R}) & \mathrm{aa} \\ 31 & \mathbf{2 9} & \mathrm{Ru}(\mathrm{II}) & 24 & \mathrm{rt} & 96 & 20(\mathrm{R}) & \mathrm{bb} \\ 32 & \mathbf{3 0} & \mathrm{Ru}(\mathrm{II}) & 0.2 & 80 & 72 & 79(\mathrm{R}) & \mathrm{cc} \\ 33 & \mathbf{3 1} & \mathrm{Ru}(\mathrm{II}) & 1 & 45 & 60 & 60(\mathrm{R}) & \mathrm{dd} \\ 34 & \mathbf{3 2} & \mathrm{Ru}(\mathrm{II}) & 7 & 45 & 93 & 97(\mathrm{R}) & \mathrm{ee}\end{array}$

${ }^{\mathrm{a}}$ Formic acid / triethylamine 5/2 used as solvent and hydride source

a. Bianchi, M.; Matteoli, U.; Menchi, G.; Frediani, P.; Pratesi, S.; Piacenti, F.; Botteghi, C. Use of DIOP in asymmetric transfer hydrogenation. J. Organomet. Chem. 1980, 198, 73.

b. a) Spogliarich, R.; Kaspar, J.; Graziani, M.; Morandini, F. Asymmetric transfer hydrogenation of ketones catalyzed by phosphine-rhodium(I) and phosphine-iridium(I) complexes. J. Organomet. 
Chem. 1986, 306, 407-412; b) Genêt, J.- P.; Ratovelomanana-Vidal, V.; Pinel, C. Asymmetric hydrogen transfer reaction of aryl ketones with chiral diphosphine-ruthenium(II) catalysts. Synlett 1993, 478-480.

c. Krause, H. W.; Bhatnagar, A. K. Asymmetric transfer hydrogenation of ketones catalyzed by chiral phosphineiridium complexes. J. Organomet. Chem. 1986, 302, 265-267.

d. Barbaro, P.; Bianchini, C.; Togni, A. Synthesis and chracterisation of ruthenium(II) complexes containing chiral bis(ferrocenyl) P3 or P2S ligands. Asymmetric transfer hydrogenation of acetophenone. Organometallics 1997, 16, 3004-3014.

e. Botteghi, C.; Chelucci, G.; Chessa, G.; Delogu, G.; Gladiali, S.; Soccolini, F. Optically-active nitrogen ligands. 3. enantioface-discriminating transfer hydrogenation of acetophenone catalyzed by rhodium(I) complexes with chiral 2-(2'-pyridyl)pyridines. J. Organomet. Chem. 1986, 304, 217 225.

f. Gladiali, S.; Pinna, L.; Delogu, G.; De Martin, S.; Zassinovich, G.; Mestroni, G. Optically active phenanthrolines in asymmetric catalysis III. Highly efficient enantioselective transfere hydrogenation of acetophenone by chiral $\mathrm{Rh}(/ 3$-alkyl phenanthroline catalysts. Tetrahedron Asymmetry 1990, 1, 635-648.

g. Zassinovich, G.; Bettella, R.; Mestroni, G.; Bresciani-Pahor, N.; Geremia, S.; Randaccio, L. Enantioselective hydrogen transfer-reactions from propan-2-ol to ketones catalyzed by pentacoordinate iridium(I) complexes with chiral schiff-bases. J. Organomet. Chem. 1989, 370, 187-202.

h. Müller, D.; Umbricht, G.; Weber, B.; Pfaltz, A. C2 Symmetric 4,4',5,5'-tetrahydro(oxazoles) and 4,4',5,5' -tetrahydro-2,2'-methylenebis(oxazoles) as chiral ligands for enantioselective catalysis. Helv. Chim. Acta 1991, 74, 232-240.

i. Jiang, Y.; Jiang, Q.; Zhang, X. A new chiral bis(oxazolinylmethyl)amine ligand for Ru-catalysed asymmetric transfer hydrogenation of ketones. J. Am. Chem. Soc. 1998, 120, 3817-3818.

j. $\quad$ Evans, D. A.; Nelson, S. G.; Gagné, M. R.; Muci, A. R. A chiral samarium-based catalyst for the asymmetric Meerwein-Ponndorf-Verley reduction. J. Am. Chem. Soc. 1993, 115, 9800-9801.

k. a) Gamez,P.; Fache, F.; Mangeney, P.; Lemaire, M. Enantioselective catalytic reduction of ketones using C2 symmetric diamines as chiral ligands. Tetrahedron Lett. 1993, 34, 6897-6898; b) Gamez, P.; Fache, F.; Lemaire, M. Asymmetric catalytic reduction of carbonyl compounds using C2 symmetric diamines as chiral ligands. Tetrahedron Asymmetry 1995, 6, 705-718; c) Bernard, M.; Guiral, V.; Delbecq, F.; Fache, F.; Sautet, P.; Lemaire, M. Structure of the diamine-Rh(I) precursor in the asymmetric hydride transfer reduction of ketones: A theoretical and experimental approach. J. Am. Chem. Soc. 1998, 120, 1441-1446; d) ter Halle, R.; Breheret, A. Schulz, E.; Pinel, C.; Lemaire, M. Chiral nitrogen-metal complexs for the asymmetric reduction of ketones. Tetrahedron Asymmetry 1997, 8, 2101-2108.

1. Gamez, P.; Dunjic, B.; Fache, F.; Lemaire, M. C2-Symmetric, psuedo C2 poly(amide) and poly(urea) as chiral inductors in in asymmetric catalysis. J. Chem. Soc., Chem. Commun. 1994, 1417-1418. 
m. Gamez, P.; Dunjic, B.; Lemaire, M. Diureas as ligands in asymmetric reduction of ketones. $J$. Org. Chem. 1996, 61, 5196-5197.

n. Touchard, F.; Gamez, P.; Fache, F.; Lemaire, M. Chiral thiourea as ligand for the asymmetric reduction of prochiral ketones. Tetrahedron Lett. 1997, 38, 2275-2278.

o. Touchard, F.; Fache, F.; Lemaire, M. Thioureas: new ligands for the metal catalysed asymmetric reduction of carbonyl compounds. Tetrahedron Asymmetry 1997, 8, 3319-3326.

p. Schwick, L.; Irelan, T.; Puntener, K.; Knochel, P. New C2-symmetric ferrocenyl diamines as ligands for ruthenium catalysed transfer hydrogenation. Tetrahedron Asymmetry 1998, 9, 1143-1163.

q. Inoue, S. I.; Nomura, K.; Hashiguchi, S.; Noyori, R.; Izawa, Y. Asymmetric transfer hydrogenation catalysed by dimine-iridium(I) complexes. Chem. Lett. 1997, 957-958.

r. Krasik, P.; Alper, H. Schiff-bases as added chiral ligands for the [ru(eta(6)- c6h6)cl2](2) catalyzed hydrogen-transfer reduction of ketones with 2- propanol. Tetrahedron 1994, 50, 4347-4354.

s. a) Hashiguchi, S.; Fujii, A.; Takehara, J.; Ikariya, T.; Noyori, R. Asymmetric transfer hydrogenation of aromatic ketones catalysed by chiral ruthenium(II) complexes. J. Am. Chem. Soc. 1995, 117, 7562-7563; b) Matsumura, K.; Hashiguchi, S.; Ikariya, T.; Noyori, R. Asymmetric transfer hydrogenation of $\alpha, \beta$-acetylenic ketones. J. Am. Chem. Soc. 1997, 119, 8738-8739.

t. Fujii, A.; Hashiguchi, S.; Uematsu, N.; Ikariya, T.; Noyori, R. Ruthenium(II)-catalysed asymmetric transer hydrogenation of ketones using a formic acid-triethylamine mixture. J. Am. Chem. Soc. 1996, 118, 2521-2522.

u. Püntener, K.; Schwink, L.; Knochel, P. New efficient catalysts for enantioselective transfer hydrogenations. Tetrahedron Lett. 1996, 37, 8165-8168.

v. Takehara, J.; Hashiguchi, S.; Fujii, A.; Inoue, S.; Ikariya, T.; Noyori, R. Amino alcohol effects on the ruthenium(II)-catalysed asymmetric transfer hydrogenation of ketones ion propan-2-ol. $J$. Chem. Soc., Chem. Commun. 1996, 233-234.

w. Palmer, M.; Walsgrove, T.; Wills, M. (1R,2S)-(+)-cis-1-amino-2-indanol: An effective ligand for asymmetric catalysis of transfer hydrogenation of ketones. J. Org. Chem. 1997, 62, 5226-5228.

x. Alonso, D. A.; Guijarro, D.; Pinho, P.; Temme, O.; Andersson, P. G. (1S, 3R, 4R)-2Azanorbornylmethanol, an efficient ligand for ruthenium-catalysed asymmetric transfer hydrogeantion of ketones. J. Org. Chem. 1998, 63, 2749-2751.

y. Langer, T.; Helmchen, G. Highly efficient new catalysts for enantioselective transfer hydrogenation of ketones. Tetrahedron Lett. 1996, 37, 1381-1384.

z. Sammakia, T.; Strangeland, E. L. Transfer hydrogenation with ruthenium complexes of chiral (phosphinoferrocenyl)oxazolines. J. Org. Chem. 1997, 62, 6104-6105.

aa. Jiang, Q.; Van Plew, D.; Murtuza, S.; Zhang, X. Synthesis of (1R,2R)-2,6-bis(1diphenylphosphinoethyl)pyridine and its application in asymmetric transfer hydrogenation. Tetrahedron Lett. 1996, 37, 797-800.

bb. Jiang, Y.; Jiang, Q.; Zhu, G.; Zhang, X. New chiral ligands for catalytic asymmetric transfer hydrogenation of ketones. Tetrahedron Lett. 1997, 38, 6565-6568. 
cc. Jiang, Y.; Jiang, Q.; Zhu, G.; Zhang, X. Highly effective NPN-type tridentate ligands for asymmetric transfer hydrogenation of ketones. Tetrahedron Lett. 1997, 38, 215-218.

dd. Yang, H.; Alvarz-Gressier, M.; Lugan, N.; Mathieu,R. Ruthenium(II) complexes containing optically active hemilabile PNO-tridentate ligands. Organometallics 1997, 16, 1401-1409.

ee. Gao, J.- X.; Ikariya, T.; Noyori, R. A rutenium(II) complex with a C2-symmetric diphosphine/diamine tetradentate ligand for asymmetric trasnfer hydrogenation of aromatic ketones. Organometallics 1996, 15, 1087-1089.

ff. Nishibayashi, Y.; Singh, J. D.; Arikawa, Y.; Uemura, S.; Hidai, M. Rhodium(I), iridium(I) and ruthenium(II) catalysed asymmetric transfer hydrogenation of ketones using diferrocenyl dichalcogenides as chiral ligands. J. Organomet. Chem. 1997, 531, 13-18.

gg. a) Hu, X. M.; Kellogg, R. M. Asymmetric reduction and Meerwein-Ponndorf-Verley reaction of prochiral aromatic ketones in the presence of optically pure 1-aryl- 2,2-dimethylpropane-1,3-diols Rec. Trav. Chim. Pays-Bas 1996, 115, 410-418; b) Krohn, K.; Knauer, B. Asymmetric induction in kinetically controlled zirconium catalysed Meerwein-Ponndorf-Verley reductions. Rec. Trav. Chim. Pays-Bas 1996, 115, 140-144; c) Knauer, B; Krohn, K. A reinvestigation of the MeerweinPonndorf-Verley reduction: a highly efficient variation using zirconium catalysts. Liebigs Ann. 1995, 677-683.

16. Palmer, M.; Walsgrove, T.; Wills, M. (1R,2S)-(+)-cis-1-amino-2-indanol: An effective ligand for asymmetric catalysis of transfer hydrogenation of ketones. J. Org. Chem. 1997, 62, 5226-5228.

17. M. Wills and J. Kenny, unpublished results.

18. Noyori, R.; Hashiguchi, S. Asymmetric Transfer Hydrogenation Catalysed by Chiral Ruthenium Complexes. Acc. Chem. Res. 1997, 30, 97-102.

19. Haack, K.-J.; Hashiguchi, S.; Fujii, A.; Ikariya, T.; Noyori, R. The catalyst precursor, catalyst, and intermediate in the Ru-II- promoted asymmetric hydrogen transfer between alcohols and ketones. Angew. Chem., Int. Edn. Engl. 1997, 36, 285-288.

20. M. Wills and A. Smith, unpublished results.

21. Bayston, D. J.; Travers, C. B.; Polywka, M. E. C. Synthesis and evaluation of a chiral heterogeneous transfer hydrogenation catalyst. Tetrahedron Asymmetry 1998, 9, 2015-2019.

22. a) Uematsu, N.; Fujii, A.; Hashiguchi, S.; Ikariya, T.; Noyori, R. Asymmetric transfer hydrogenation of imines. J. Am. Chem. Soc. 1996, 118, 4916-4917; b) Wang, G.- Z.; Bäckvall, J.-E. Ruthenium-catalyzed transfer hydrogenation of imines by propan- 2-ol. J. Chem. Soc., Chem. Commun. 1992, 980-982; c) Ahn, K. H.; Ham, C.; Kim S.-K.; Cho, C.-W. Practical synthesis of chiral sultam auxiliaries: 3-substituted 1,2-benzisothiazoline 1,1-dioxides. J. Org. Chem. 1997, 62, 70477048.

23. a) ter Halle, R.; Schulz, E.; Lemaire, M. Heterogeneous enentioselective catalytic reduction of ketones. Synlett 1997, 1257-1258; b) Breysse, E.; Pinel, C.; Lemaire, M. Use of heterogenized dialdimine ligands in asymmetric transfer hydrogenation. Tetrahedron Asymmetry 1998, 9, 897900 . 
24. Hashiguchi, S.; Fujii, A.; Haack, K.-J.; Matsumura, K.; Ikariya, T.; Noyori, R. Kinetic resolution of racemis secondary alcohols by $\mathrm{Ru}(\mathrm{II})$-catalysed hydrogen transfer. Angew. Chem. Int. Ed. Engl. 1997, 36, 288-290.

Samples Availability: available from the authors.

(C) 2000 by MDPI (http://www.mdpi.org). Reproduction is permitted for noncommercial purposes. 